\title{
Experimental investigation and statistical analysis of additively manufactured onyx-carbon fiber reinforced composites
}

\author{
P. Sethu Ramalingam ${ }^{1,2 *}$, K. Mayandi ${ }^{2}$, N. Rajini ${ }^{2 *}$, A. Abdul Munaf ${ }^{1}$, \\ S. K. Rajesh kanna ${ }^{1}$, Sikiru Oluwarotimi Ismail ${ }^{3}$, Suchart Siengchin ${ }^{4}$, Faruq Mohammad ${ }^{5}$, \\ Hamad A. Al-Lohedan 6 \\ ${ }^{1}$ Department of Mechanical Engineering, Rajalakshmi Institute of Technology, Chennai, India. \\ ${ }^{2}$ School of Automotive and Mechanical Engineering, Department of Mechanical Engineering, \\ Kalasalingam Academy of Research and Education, Krishnankoil 626126, Tamilnadu, India. \\ ${ }^{3}$ Center for Engineering Research, Department of Engineering, School of Physics, Engineering \\ and Computer Science, University of Hertfordshire, AL10 9AB, England, United Kingdom. \\ ${ }^{4}$ Department of Mechanical and Process Engineering, The Sirindhorn International Thai-German \\ Graduate School of Engineering (TGGS), King Mongkut's University of Technology North \\ Bangkok, 1518 Wongsawang Road, Bangsue, Bangkok 10800, Thailand. \\ ${ }^{5,6}$ Department of Chemistry, College of Science, King Saud University, P.O. Box 2455, Riyadh, \\ Kingdom of Saudi Arabia 11451.
}

\section{*Corresponding authors:}

P. Sethu Ramalingam, E-mail: sethu1412@gmail.com, Telephone/Fax: +919894770095

N. Rajini, E-mail: rajiniklu@gmail.com, Tel.: +91 99421 39392; Fax: +91 4563289042. 


\section{Abstract}

Availability of additive manufacturing (AM) has influenced the scientific community to improve on production and versatility of the components created with several associated technologies. Adding multiple substances through superimposing levels is considered as a part of threedimensional (3D) printing innovations to produce required products. These technologies are experiencing an increase in development nowadays. It requires frequently adding substance and has capacity to fabricate extremely complex geometrical shapes. However, the fundamental issues with this advancement include alteration of capacity to create special products with usefulness and properties at an economically viable price. In this study, significant procedural parameters: layer designs/ patterns (hexagonal, rectangular and triangular) and infill densities (30, 40 and $50 \%$ ) were considered to investigate into their effects on mechanical behaviors of fused deposition modeling $(\mathrm{FDM})$ or 3D-printed onyx-carbon fiber reinforced composite specimens, using a high-end 3D printing machine. Mechanical (tensile and impact) properties of the printed specimens were conclusively analyzed. From the results obtained, it was observed that better qualities were achieved with an increased infill density, and rectangular-shaped design exhibited an optimum or maximum tensile strength and energy absorption rate, when compared with other counterparts. The measurable relapse conditions were viably evolved to anticipate the real mechanical qualities with an accuracy of $96.4 \%$. In comparison with other patterns, this was more closely predicted in the rectangular design, using regression models. The modeled linear regression helps to define the association of two dependent variables linked with properties of the dissimilar composite material natures. The models can further predict response of the quantities before and also guide practical applications. 
Keywords: Onyx-carbon fiber composites, Additive manufacture (AM), 3D printing, Fused deposition modeling (FDM), Mechanical properties, Statistical analysis.

\section{Introduction}

\subsection{Additive Manufacturing}

The possibility of printing layer-by-layer product, material into parts, is a developmental method for additive manufacturing (AM). Diverse innovative techniques associated with AM are subsequently highlighted.

- Fused deposition modeling (FDM)

- Direct ink writing (DIW)

- Stereolithography (SLA)

- Laminated object manufacturing (LOM)

- Digital light processing (DLP)

- Photopolymer jetting (Poly Jet)

- Selective laser sintering (SLS)

- Binder jetting (3DP).

Nowadays, AM is capable of manufacturing materials, such as plastics, metals, polymer and composite materials. Design freedom, reduction of material waste and manufacturing cost are the advantages that make AM an attractive technology to the manufacturing industries. AM provides freedom for engineers to design more complex geometries without restricted by manufacturing process. All AM techniques operate in a similar principle. The processes of AM, commonly known as 3D printing, starts with designing a geometry of a component with aid of 3D computer-aided design (CAD) software. Then, the file is converted into a stereolithography 
(SLA) file format, commonly used by all AM machines. Thereafter, the design is chopped into thin layers by slicing software. The required part information, such as layer thickness, tool path, part orientation, type of material, among others are prepared with help of the software and included in the SLA-file. The SLA-file is then directed to the AM machine and used as a command when fabricating the designed part [1]. A tensile test and analysis of the carbon fiber (CF) reinforced composite parts manufactured by additive manufacturing process have been reported [2-5]. A proposal that includes multi-material 3D and 4D-printed objects and reflects the current shortcomings and potential of AM process was reviewed [6]. Conventionally, 3Dprinted materials are fabricated with virgin polymer filament or particle reinforced 3D filament. The novelty of our work includes the fact the materials were fabricated using carbon short fiber reinforced with onyx matrix 3D filament. The fiber reinforced 3D filament materials was used in a special purpose machine, named Markforged X7 3D printing machine for making specimen with various process parameters and conditions, such as infill densities (30, 40 and 50\%) and Infill patterns (triangular, rectangular and hexagonal).

\subsection{Fused deposition modeling}

The fused deposition modeling (FDM) method is one of the growing technologies in AM. It produces functional prototypes of a complex structure made of polymer and can be made safely in a closed environment. The 3D printing uses a continuous flow filament of thermoplastic fabric. The working process is a filament fed through the extruder head, which is pre-heated. The head of the extruder is computer-controlled, and it moves based on the shape of the object to be fabricated. The filament which is fed into the system gets heated, and a fine layer of a filament gets released from the extruder. The software regulates the movement of the extruder. With the 
3D printing software, different parameters, such as infill rate, infill pattern, the thickness of the layer, temperature and speed can be defined to desired values.

Zaman et al. [7] studied the parameter variation based on the filament and the machine used. There are some assorted thermoplastics accessible as filaments. For example, acrylonitrile butadiene styrene (ABS), poly lactic acid (PLA), polystyrene (PS), polyvinyl alcohol (PVA), polyethylene terephthalate (PET), polyamide (nylon) and onyx. The main advantage of FDMAM technology is a huge range of substances that can be used. It is a quiet, non-toxic and officefriendly process and needs no clean-up. Fernandez-Vicente et al. [8], in their analysis, discussed number of infill patterns along with thickness with an objective of reducing production rate as well as material intake. The material used was ABS and the infill patterns, in addition to density, were varied. Then, various tests were performed on the specimen, include tensile test and examination was carried out according to ASTM 3039 standard. The results obtained from this evaluation showed that that change in the infill density produced a challenge in tensile durability.

In addition, Camargo et al. [9] analyzed the mechanical properties (impact energy, strength, tensile and flexural) of PLA-graphene parts manufactured by FDM process. An improvement on mechanical behaviors was recorded with an increased in linear layer thickness; both tensile and flexural strengths increased with an increased infill, unlike impact energy. Also, evaluation of relationship between printing time/weight and mechanical behaviors was considered. Villalpando et al. [10] researched on variety of parametric structures, develop orientation as well as internal densities of ABS materials. The result showed that the actual thermoplastic product showed a delicate conduct when it was in spinning elastic range. The added internal structures provided completely new possibilities in order to provide balance between material use and strength. Alafaghani et al. [11] experimented with some actual parameters: construction path extrusion, 
bed temperature and level elevation. A complete 18 test specimens were printed, using various running parameters. The study on tensile strength was performed according to ASTM D638 requirements to acquire the mechanical properties of all the specimens. Dimensional precision showed to be influenced by the formation of extrusion temperatures for direction, layer rates (above infill percentage) and the printing rate. Lanzotti et al. [12] analyzed three different essential variable layers width infill direction and perimeters of shell. A total of 60 specimens were extracted from the combinations associated with selected details printed on a RepRap I3 with PLA material. Screening was carried out on tensile screening machines, under a cellular load of $1100 \mathrm{~N}$. Concerning the ultimate tensile strength (UTS) values, a drop in strength with the infill direction of $90^{\circ}$ was observed, but it was increased as the perimeters increased. An early improvement was evident when the width of the shell was around $0.18 \mathrm{~mm}$. Hart et al. [13] tested some specimens with multiple directions, with and without graphite reinforcement. Comparison of the results of specimens with $90^{\circ}$ focused continuous feeding with that of the $0^{\circ}$ specimens, there were 52,60 and 62\% decrease in flexural modulus, yield and tensile strengths, respectively.

Li et al. [14] discussed the significantly improvement in FDM 3D-printed parts by ultrasonic strengthening process. The influence of both ultrasonic strengthening time and pressure on tensile response of the printed parts was studied. The results depicted that tensile strength and Young's modulus increased by 11.3 and $16.7 \%$, respectively. Tanikella et al. [15] developed the traction strength sample based on ASTM D638. The assessment on many materials showed that the tensile strength of the 3D-printed specimens depended primarily on the weight from the specimen. Ziemian et al. [16] investigated into the tensile assessments of FDM dog bone specimens, with four particular raster directions based on ASTM regular D638 type 3. Maximum 
ultimate stress for every direction of the raster was obtained for the specimen printed. Hanon et al. [17] analyzed the effect of presence of bronze in bronze/PLA composite and also discussed the 3D printing orientation on bronze/PLA composite tribology. The results depicted that both mechanical and tribological properties of the 3D-printed composite samples depended on various printing orientations. Martínez et al. [18] reported the actual printing direction using the FDM. A total of 45 samples were fabricated within altitudes of $0^{\circ}, 45^{\circ}$ and $90^{\circ}$, with xy- and z-planes of $45^{\circ}$ and $90^{\circ}$, respectively. Each of the tensile, compression and flexural tests has 15 samples. The investigation reported the outcomes of the compression as well as tensile tests of ABS synthetic materials. The results showed that with printing at $90^{\circ}$ in xy-direction, high tensile strength was obtained and analyzed with other altitudes. Printing at $0^{\circ}$ in the xy-plane considerably increased the compressive and flexural strengths of the materials, when compared with other orientations.

Rajpurohit and Dave[19]predicted and optimized the tensile strength in FDM based 3D printing, using an adaptive network-based fuzzy inference system (ANFIS). The fluffy disturbance adaptable system used both nerve organs organized just as a fuzzy thinking to create a mapping among guidance and response. With ANFIS, the variables used for the fluffy structure continued to be classified, using a neural system. The created model enabled estimation of the tensile strength as a functionality of FDM builds, which consists of raster position, coating stature and raster width. The new reaction inferred that the constructed domain significantly impacted the rigidity related to the FDM part. The created model confirmed consistency in malleability, with 20 examples of real testing data. ANFIS item was built about foreseen specific elastic toughness obtained from the result from the experimentation. Shahrain et al. [20] studied the effect of modifications of an extensive list of procedure parameters upon part scalability and tensile strength associated with fused filament fabricated (FFF) or printed components. Taguchi 
type of experiment was employed to develop an excellent experimental strategy in the analysis. The specimen was printed, their tensile strengths were measured before breakage and results were analyzed. Kowalczyk et al. [21] established the effects of strength associated with low atomic weight of polybutadiene dispersed within the high impact polystyrene (HIPS) and ABS. The tests were performed on an electron microscope. The result showed that an increase in lowmolecular weight did not improve the strength, because the less molecular weight polybutadiene lost its effectiveness, such as a local plasticizer of trend fibrils.

Alkayyali \& Ahmadi [22] fabricated the microfluidic chips using 3D printing. In their work, a simple, fast, and inexpensive step is introduced to fabricate polydimethylsiloxane (PDMS) microfluidic chips using enhanced internal scaffold removal (eISR). Tang et al. [23] investigated the various $3 \mathrm{D}$ printing parameters on a transdermal drug delivery system with milliprojections printed using poly (lactic acid) (PLA). It was found that the smaller nozzle orifice and increased spacing between milliprojections produced better surface finish but had no significant effect on part accuracy.Shilpesh et al. [24] analyzed the influence of method of progression factors, viz; coating, thickness as well as raster height on the flexural property associated with PLA. Samples were printed with PLA materials, using Tissot apparatus. The actual sample within this work was subjected to flexural strength test in accordance with a regular ASTM D790 standard. The result showed the superior flexural value observed in $0^{\circ}$ raster position at $0.1 \mathrm{~mm}$ layer elevation and $0.6 \mathrm{~mm}$ raster size. Wicaksono et al. [25] printed an interior geometry of a PLA material, using a triangular and hexagonal arrangement with various size of individual uniform pivot of 4.5 and $9.0 \mathrm{~mm}$ and width difference of 1000 and $2000 \mu \mathrm{m}$, respectively. Mechanical properties of the developments included ductile and curving quality, assessed by flexural test according to ASTM D790 and ASTM D638 normal. The mechanical properties and scanning electron microscope 
(SEM) micrographs of the two printed PLA and PLA/CF materials were discussed [26]. Suresh et al. [27] analyzed the results obtained from the impact test of carbon fiber reinforced nanoclay filled interpenetrating polymer network (IPN) matrix composites. From the 3D-printed carbon fiber reinforced PLA, maximum bending strength and modulus of $335 \mathrm{MPa}$ and $30 \mathrm{GPa}$ were obtained with a fiber content of $27 \%$ [28], while important process parameters were analyzed for the wear strength of the components fabricated by FDM process [29].Pastrnak et al. [30] examines the scaling effects present in uniaxial tensile test specimens of molded high-density polyethylene (HDPE), with geometries ranging from Types I to IV of ASTM D638 to ASTM D3039. In the tensile mechanical properties of ASTM D638 Types II and IV geometries as statistically similar to those of ASTM D3039 samples. Kim et al. [31] studied the effects of printing temperature, speed, and layer morphology on the layer-by-layer 3D-printed structures and their mechanical properties were considered. Results showed that the PLA-based 3D structures possessed the favorable mechanical performance with 34\% higher Young's modulus and 23\% higher tensile strength in comparison to the ABS based 3D structures.

Based on the aforementioned reviews, it was understood that study on 3D-printed onyxcarbon fiber reinforced composites is rare and scarce, especially experimentally and statistically. Therefore, this present work investigated into the influence of significant procedural parameters, such as hexagonal, rectangular and triangular layer patterns/designs as well as infill densities of 30, 40 and 50\% on mechanical (tensile and impact) behaviors of the FDM/AM onyx-carbon fiber reinforced composite specimens, using a high-end 3D printer. 


\section{Experimentation}

\subsection{Materials and methods}

Carbon filaments are utilized in the creation of superior composite applications, as most parts of several systems. Carbon fiber reinforced composites have high strength to weight ratio, stiffness, corrosion and wear resistance. CF reinforced composite is attractive in the aerospace, automotive, and athletics sectors, among others. Some of the parts made of CF composite materials include helicopter mower blades, engine nozzles, radar devices, race automobile brakes and wind turbine blades. The usefulness of an onyx composite material depends on fiber nature, orientation and methods of production. For instance, the elasticity of modulus, along zero - level of a traditionally produced carbon fiber may be three times that of the modulus of transverse. The actual directional strength varies for the reinforcing fiber, which makes composite material to have an anisotropic property.

Furthermore, high modulus fibers possess low stress at failure when compared with lower modulus materials. In addition, as one of the important factors, the amount of fraction associated with reinforcing and matrix in a composite system determines the properties of the composite materials. Higher volume small fraction fiber offers higher strength and rigidity. Also, the length of the actual reinforcing fiber affects the strength of the fibers. To obtain a highly effective strength and stiffness, the size of the fiber must be longer than the crucial fiber size. The required length depends on size of the fiber content filament, tensile strength and fiber-matrix bonding energy (shear and yield strength of the matrix). Onyx-fiber reinforced PLA composites were used in this investigation. Both onyx and carbon fiber filaments were purchased from Markforged Industries. Onyx is a blend of engineering nylon and chopped carbon fibers. Onyx is 1.4 times sturdier and more stable than any continuous fiber that can reinforce materials, such as 
ABS. It has a great quality surface area finish. The actual chopped materials, onyx materials were put into 3D-printed parts, offering nano-carbon reinforcement to create parts with relative strength and desirable sizes. It is two times strong, because of the presence of ABS and micro carbon reinforcement.

\subsection{Machine used}

Markforged X7 printer invented by the Markforged $®$ is unquestionably the highest model of their all-out modern 3D printers, as shown in Fig. 1(a). The machine was fitted to layer of two fiber materials with its two spouts. Nylon and onyx were the two plastic materials utilized in Mark-X7. Onyx can be used alone, but it tends to be stronger when used with consistent filaments. Plastic materials rapidly absorbs dampness, and wet plastic segments lacking obstruction. It must, subsequently, contained in a firmly fixed shell. The 3D printer has two infeeders to introduce fiber into the machine during printing (Fig. 1b).

The most significant size that can be worked by mark Two is 33 x $27 \times 20 \mathrm{~cm}$ (x-y-z, separately). Imprint X7 has pair spouts; one spout expels the network material of either nylon or onyx, while the second spout fortifies filaments. The fiber material was warmed to its glass transition at the spout and expelled at a steady rate, while the printing head moved in the xyplane. Unlike other AM machines, no warmth required by the bed, and parts were printed altogether after model creation was done. Imprint $\mathrm{X} 7$ began printing, first in the dividers and afterward infill design inside the dividers started with floor layers. The first layer of the floor prints was done with a direction of +45 degrees and followed by -45 degrees. The path of the grid material at +45 degrees was predefined, and the client has constraints of printing in different directions. Also, there are more choices, such as rectangular, triangular, hexagonal and stiff infill 
designs, as the present focus of this study. Markforged ${ }^{\circledR}$ has built up its cloud-based cutting programming to transfer the STA-record and make required print settings. It supports various material and settings, include layer thickness, fiber direction, design thickness and a few choices of fiber layers. Besides, internal layer-by-layer fiber format alteration can be determined physically under interior view setting.

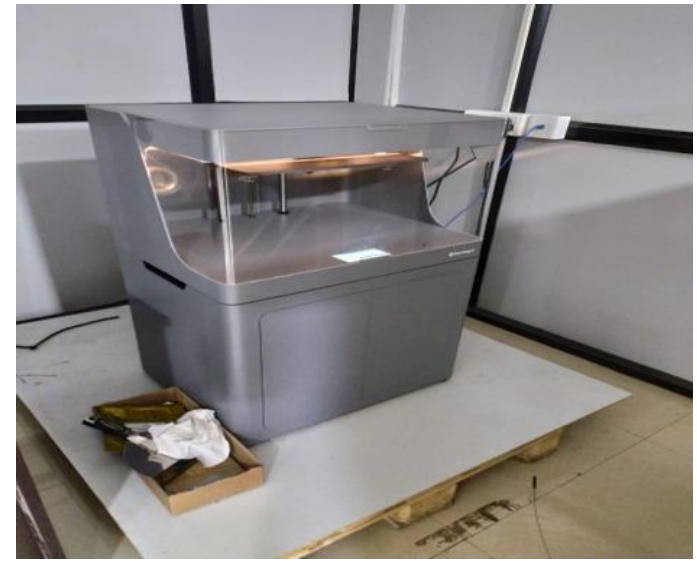

(a)

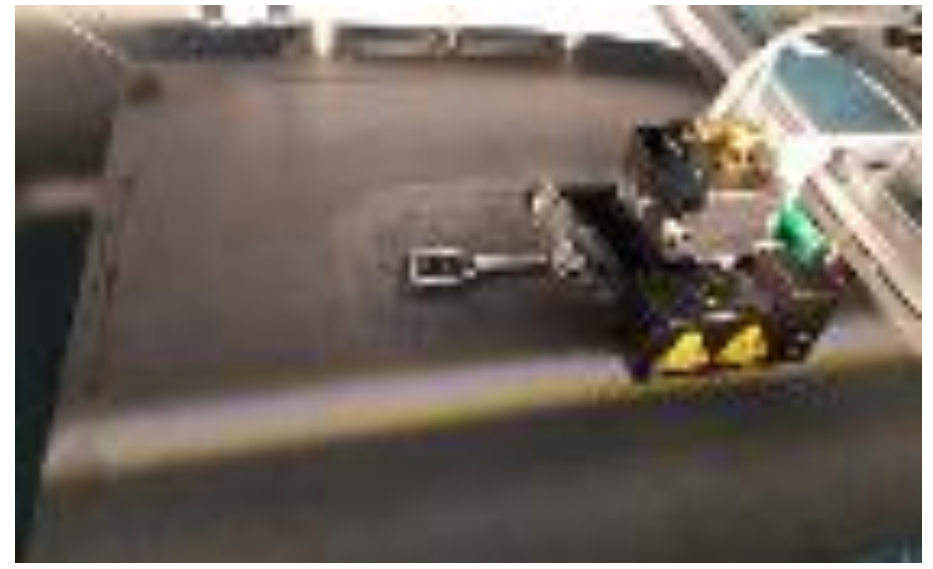

(b)

Fig. 1 (a) Markforged X7 3D printing machine and (b) specimen during printing

\subsection{Preparation of composite samples}

The fused fiber manufacturing technique was used to print the specimens with various parameters, such as infill design and thickness. Sum of 9 specimens were fabricated, using Markforged X7 machine. The various percentages of infill density, infill patterns and their nomenclatures used for both tensile and impact test specimens are presented in Table 1. The layer height of $0.125 \mathrm{~mm}$ was fixed for all specimens. All the specimens were printed in Monotech industry. It is located in Ambatur, Chennai, Tamilnadu, India. 
Table 1 Various specimens for tensile and impact tests

\begin{tabular}{cccc}
\hline \multirow{2}{*}{ Infill density $(\%)$} & & Infill pattern & \\
\cline { 2 - 4 } & Hexagon & Rectangle & Triangle \\
\hline 30 & $\mathrm{H} 1$ & $\mathrm{R} 1$ & $\mathrm{~T} 1$ \\
50 & $\mathrm{H} 2$ & $\mathrm{R} 2$ & $\mathrm{~T} 2$ \\
\hline
\end{tabular}

From Table 1, H1, H2 and $\mathrm{H} 3$ are the specimens which were prepared at infill densities of 30, 40 and $50 \%$ by hexagon pattern, respectively. While, R1, R2 and R3 were specimen modelled at infill densities of 30, 40 and $50 \%$ by rectangular pattern. Similarly, T1, T2, T3 are the third set of specimens prepared at infill densities of 30, 40 and $50 \%$ with a triangular design. The specimens are shown in Fig. 2.

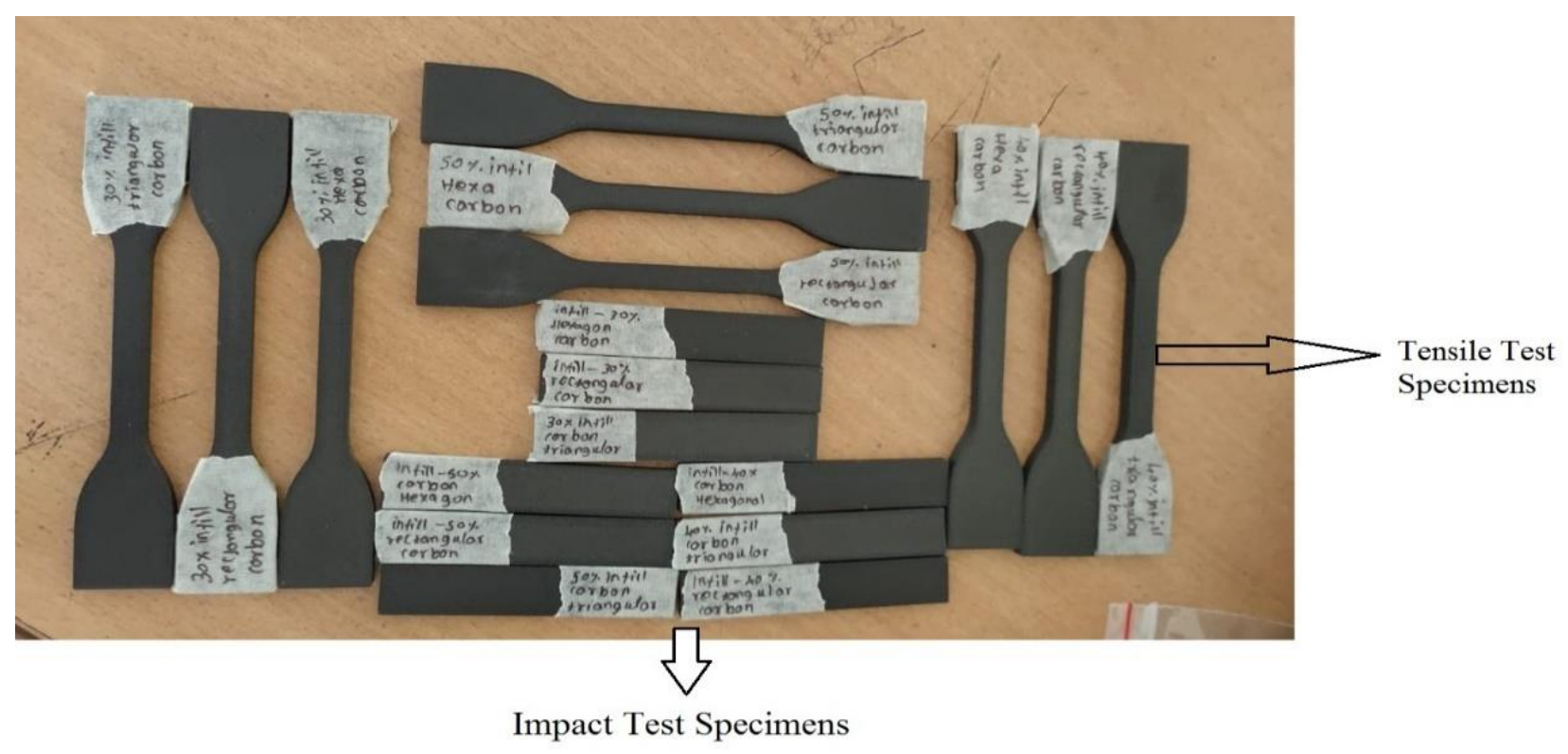

Fig. 2 Tensile and impact specimens 


\subsection{Mechanical characterization}

After the models have been developed, they were subjected to mechanical testing. Tensile strengths and moduli of all trial specimen were assessed and the influencing energy in the specimens was furthermore evaluated. The tensile tests were performed on a Tinus Olson general testing equipment in accordance with ASTM D638 standard, using a speed rate of $3 \mathrm{~mm} / \mathrm{min}$.

\subsection{Statistical analysis}

Regression analysis is an analytical tool that allows measurement of several independent features linked to a type variable. Regression form using one primarily based changeable and even more than a single non-partisan issue is a variety of regression. Typically, the principle intended for a compound regression study is generally $[32,33]$.

It was formatted with Eq. (1).

$$
X^{1}=a_{0}+a_{1} Y_{1}+a_{2} Y_{2}+\ldots .+a_{n} Y_{n}
$$

Where $\mathrm{X}^{1}$ represents the estimated value of $\mathrm{X}$, required factor, $\mathrm{a}_{0}$ denotes $\mathrm{X}$ intercept, associated with $\mathrm{X}$, whenever all the impartial variables tend to be zero. Also, $\mathrm{a}_{1}$ and $\mathrm{a}_{2}$ stand for the slopes of $Y_{1}$ and $Y_{2}$, respectively.

Correlation analysis requires several arithmetical processes to compute the actual relationship among dependent variables as well as non-partisan factors. The coefficient of relation is associated with the degree of a direct connection between the two parameters. This analysis represents the symbol of $R$ highlights the correlation coefficient, ranges from -1 to +1 . It shows the intensity or degree of the relationship concerning two quantities. Close to zero and \pm 1 indicate a small, reliable, functional and the unfavorable relationship between variables [34,35]. 


\section{Results and discussion}

\subsection{Tensile analysis}

Infill rate is related to the absolute volume level required for the creation procedure. The specimens were fabricated according to ASTM standard with three different designs: rectangular, triangular, as well as hexagonal shapes with infill percent densities of 30, 40 and 50\%, each. The results of the tensile strengths obtained from the composite samples are depicted in Figs 3(a) and (b). It was observed that infill density of 50\% and rectangular pattern provided the maximum tensile strength of $154.66 \pm 4.4 \mathrm{MPa}$, when compared with other two infill densities and patterns. The results established the relationship or connection among the infill density, pattern and the tensile strength of the composite sample.

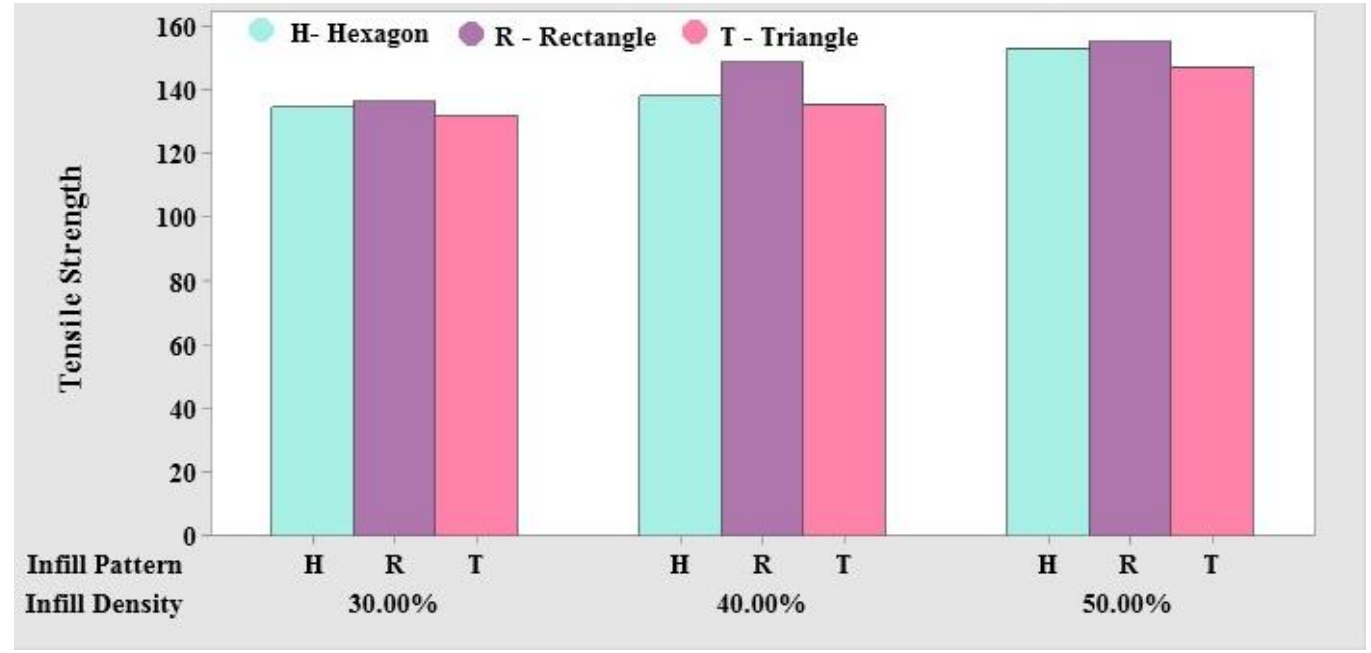

(a) 


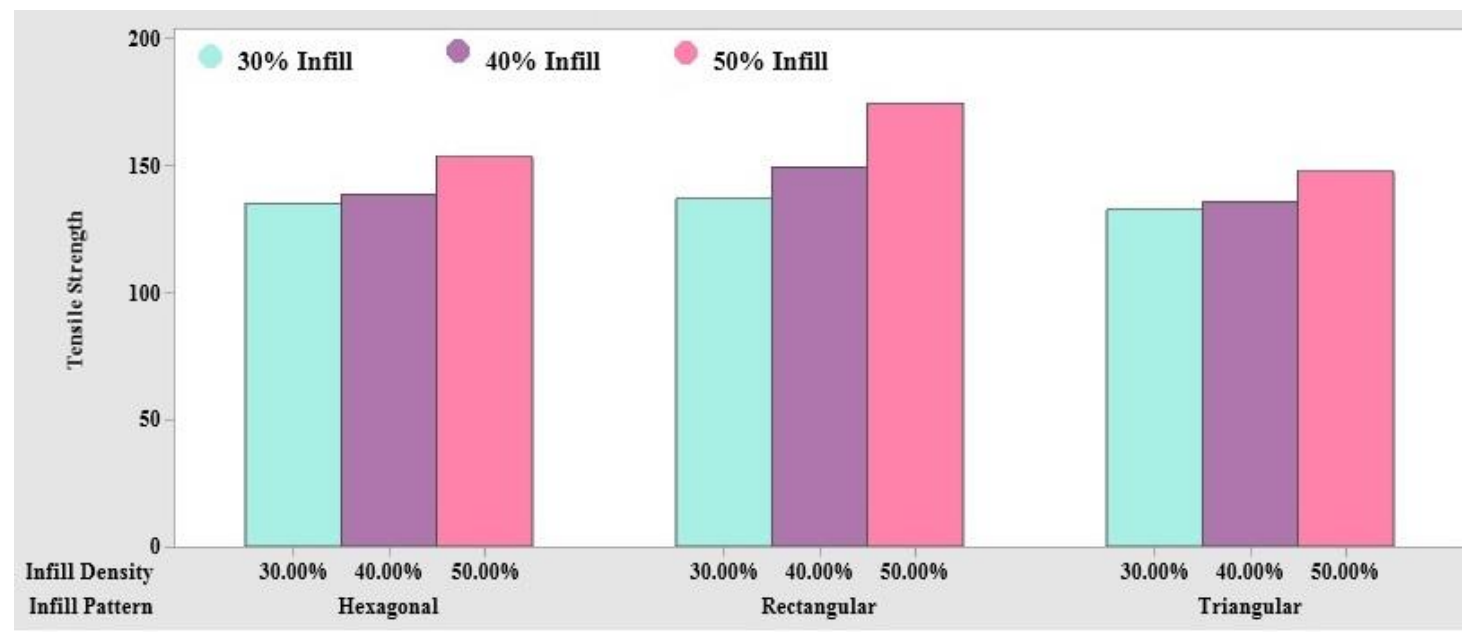

(b)

Fig. 3 Tensile strengths of various infill: (a) densities and (b) patterns

\subsubsection{Regression analysis of tensile strengths}

The analysis of regression is one of the statistical methods for predicting the value of change in one variable to another. The tensile energies obtained for the rectangular, triangular and hexagonal designs are illustrated in Figs 4(a)-(c). The forecast values for the three patterns are expressed from Eqs (2)-(4). The most estimated rigidity was obtained at $154.66 \pm 4.4 \mathrm{MPa}$ for a rectangular pattern with infill density of $50 \%$. In the meantime, the minimum estimated elasticity occurred at 133.24 MPa with triangular design at infill density of 30\%. Importantly, the tensile strength of the onyx-carbon fiber reinforced composite improved moderately, as the percentage of infill density improved from 30 to $50 \%$. The value of $R^{2}$ for the optimum rectangular pattern and tensile strength was 0.9585 , which was virtually close to the fitting range while outperforming others. The tensile strength regression models for the three patterns are expressed as Eqs (2)-(4).

Hexagon, $\mathrm{X}=106.1+0.9 \mathrm{Y}_{1}$ 
Rectangle, $\mathrm{X}=110.18+0.911 \mathrm{Y}_{1}$

Triangle, $\mathrm{X}=110.6+0.6 \mathrm{Y}_{1}$

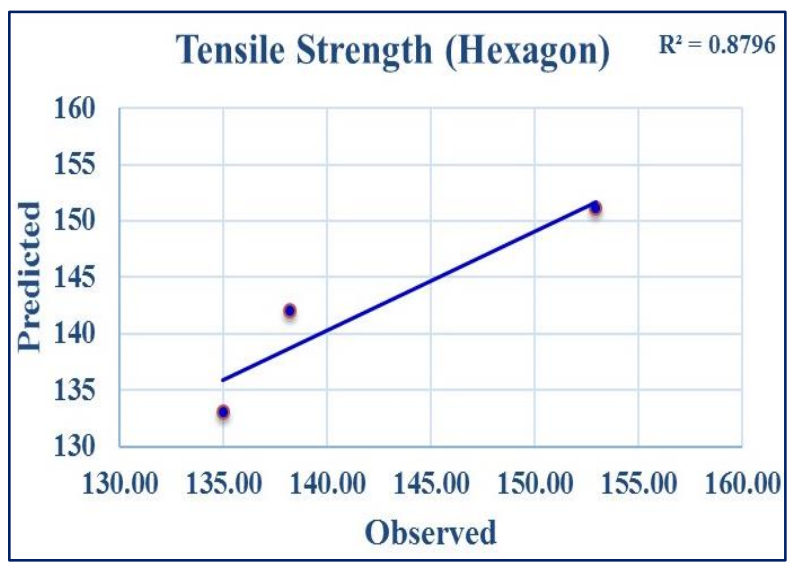

(a)

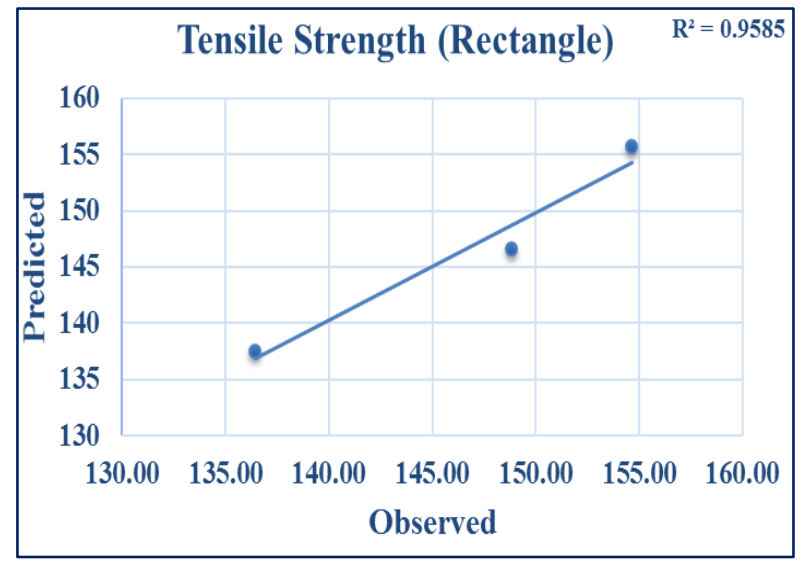

(b)

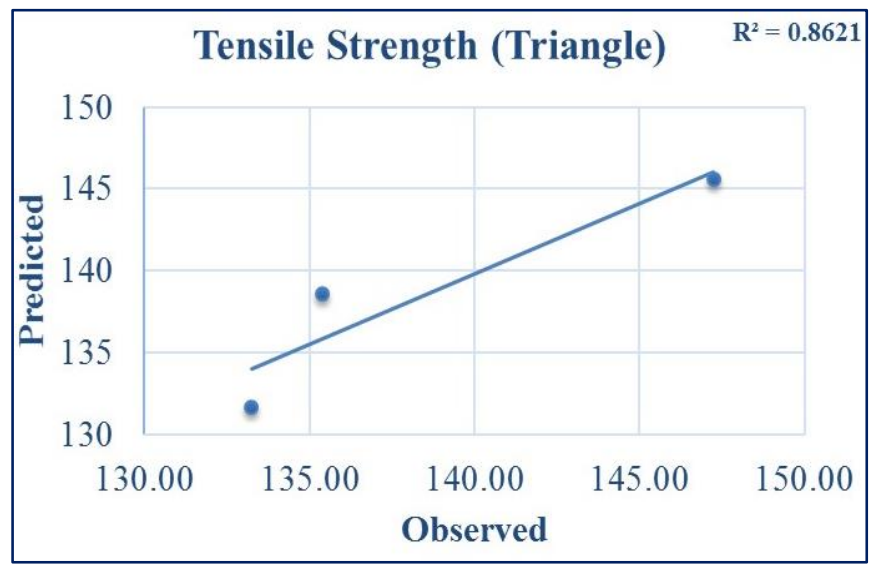

(c)

Fig. 4 Predicted tensile strengths of (a) hexagon, (b) rectangular and (c) triangular patterns

\subsection{Analysis of modulus of elasticity}

Figs 5(a) and (b) depict the real tensile moduli of the 3D-printed composite samples. It was observed that the elastic moduli of the composite samples improved with an increase in the infill 
percent. From the results obtained, an improved tensile modulus of $174.16 \mathrm{MPa}$ was achieved from infill density of $50 \%$ and layer peak of 0.125 with the rectangular design. More tensile modulus can be obtained with an increase in the infill density, as the plasticity of the composite materials tends to improve or increase.

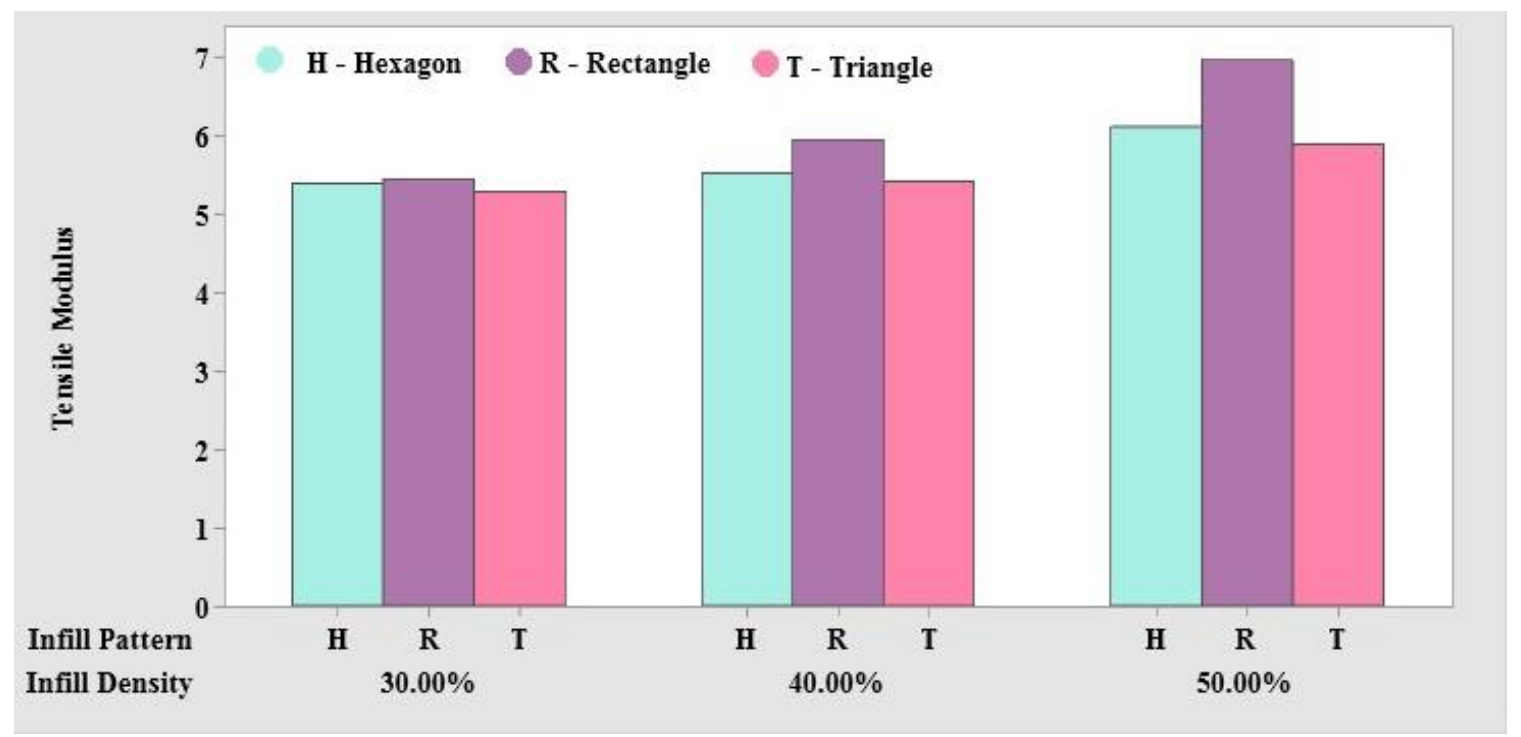

(a)

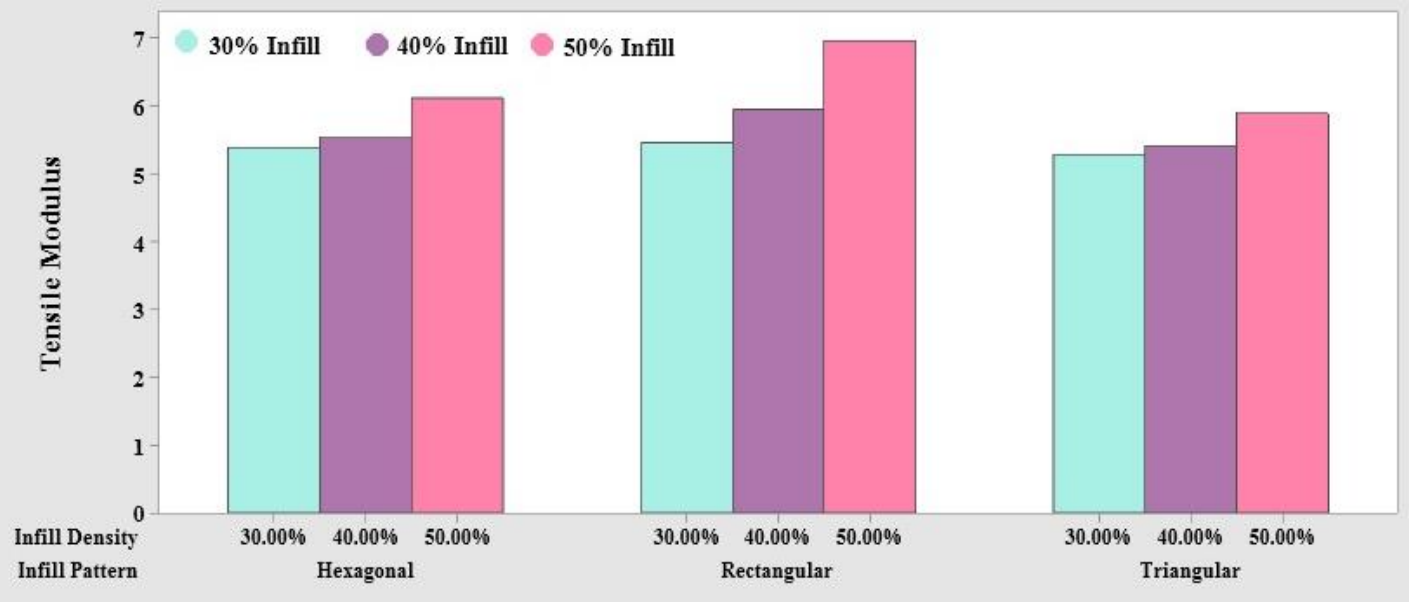

(b)

Fig. 5 Tensile moduli of various infill (a) densities and (b) patterns 


\subsubsection{Regression analysis of modulus of elasticity}

To predict higher tensile modulus and composite performance, regression analysis was carried out. It implies that $R^{2}$ values of three patterns were forecast, using Eqs (5)-(7). Therefore, the highest value of $R^{2}$ for tensile modulus of rectangular pattern was 0.9623 , when compared with the $R^{2}$ values of both triangular and hexagonal samples, as shown in Figs 6(a)-(c). The modulus of elasticity regression models for the three patterns are expressed as Eqs (5)-(7).

Hexagon, $\mathrm{X}=4.224+0.0364 \mathrm{Y}_{1}$

Rectangle, $\mathrm{X}=3.107+0.0755 \mathrm{Y}_{1}$

Triangle, $\mathrm{X}=4.332+0.03 \mathrm{Y}_{1}$

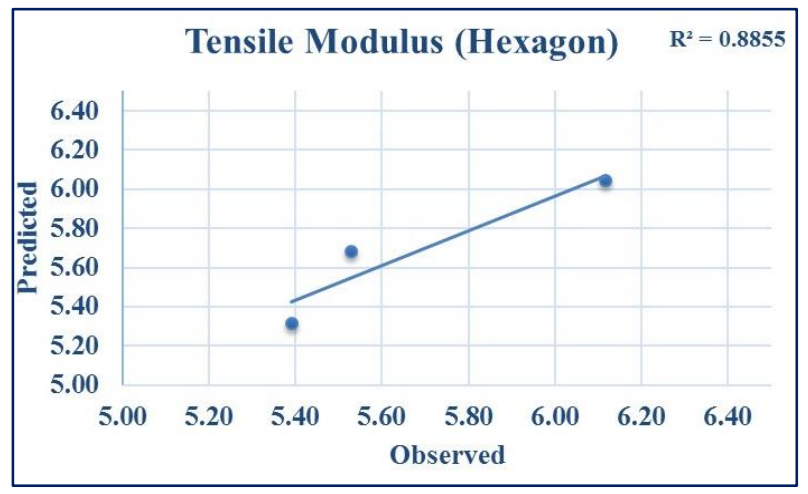

(a)

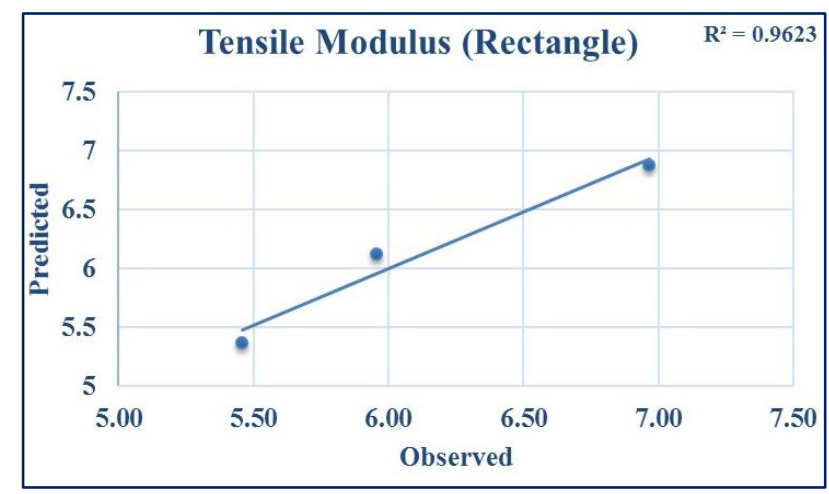

(b)

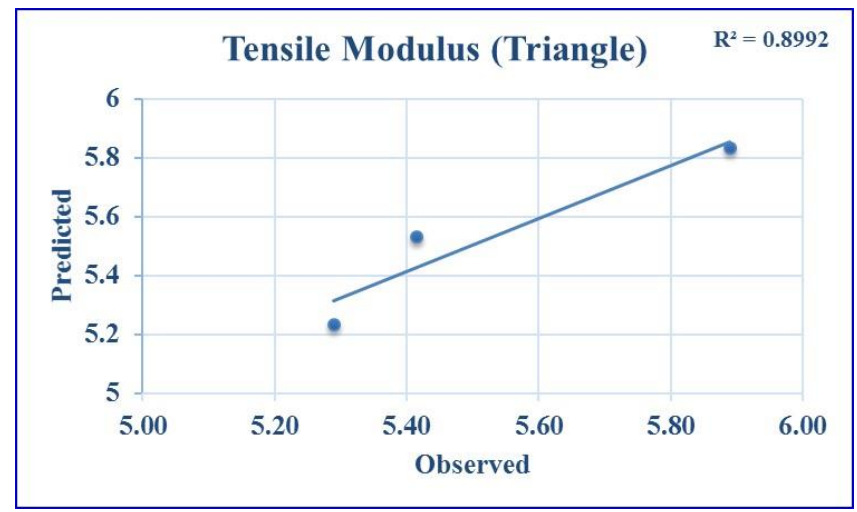

(c)

Fig. 6 Predicted tensile moduli of (a) hexagon, (b) rectangular and (c) triangular patterns 


\subsection{Energy absorption (impact analysis)}

Considering the influence of various infill densities of 30,40 and $50 \%$ for three patterns on impact resistance of the composite samples, their energy absorption values were obtained for the samples according to ASTM standard. The results obtained are depicted in Figs 7(a) and (b). It was evident that the energy absorption increased with an increase in the infill thickness. It was more pronounced at 7.9 Joules with infill density of $50 \%$ and rectangular pattern. Therefore, the rectangular design has the greatest advantage in terms of impact load or energy absorption.

(a)

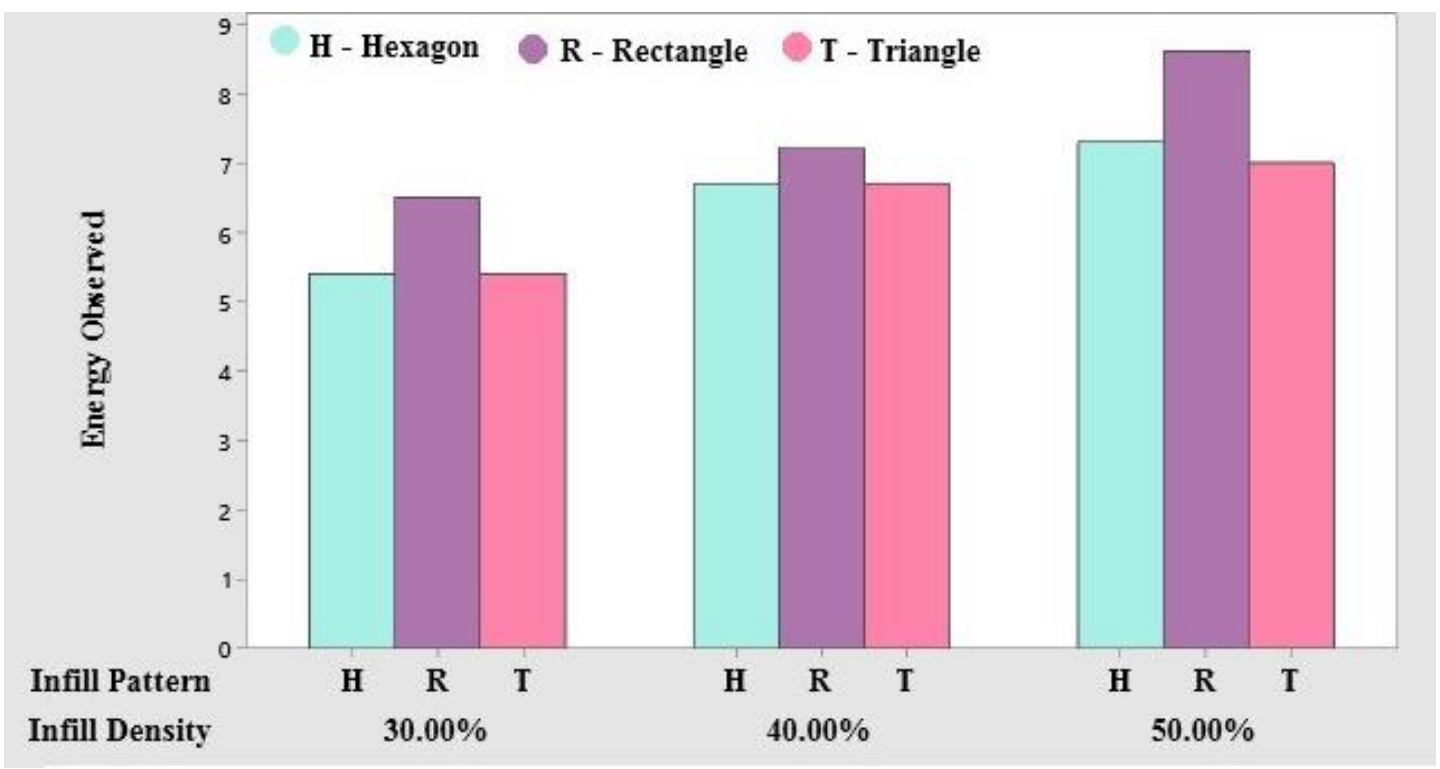




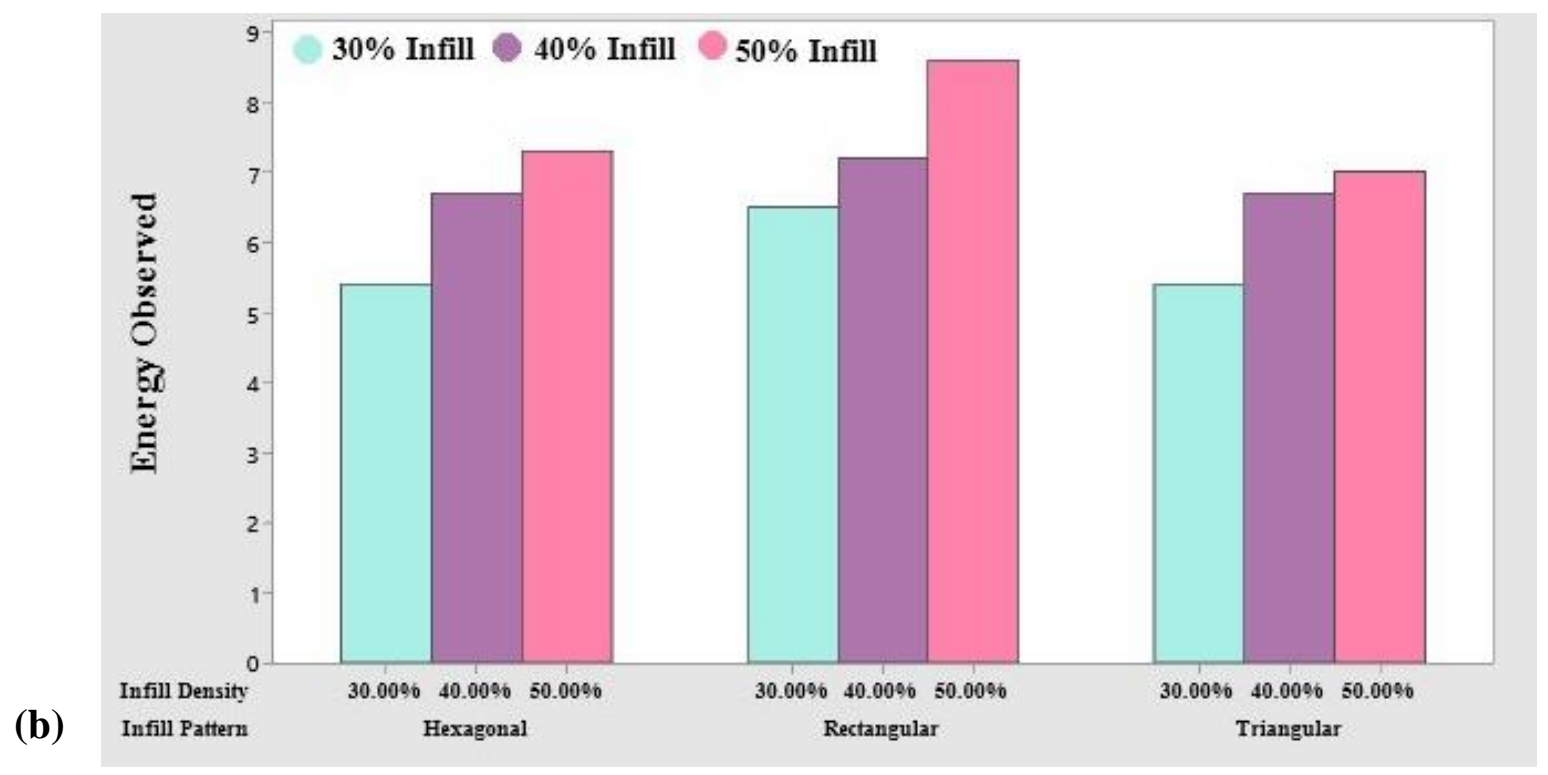

Fig. 7 Energy absorption observed with various infill (a) densities and (b) patterns

\subsubsection{Regression analysis of energy absorption}

Using the regression analysis method to predict the impact energy absorbed by the various composite samples, the results obtained are shown in Figs 8(a)-(c). The absorption energy levels for all trends were analyzed. Similarly to the previous regression analysis, Eqs (8)-(10) were modeled from the experimental impact results obtained from this study. It was observed and further confirmed that the optimal effects of the actual specimen built from rectangular design provided most accurate results, with estimated value of $R^{2}$ to be 0.9643 . The energy absorption regression models for the three patterns are expressed as Eqs (8)-(10).

Hexagon, $\mathrm{X}=2+0.11 \mathrm{Y}_{1}$

Rectangle, $\mathrm{X}=3.233+0.105 \mathrm{Y}_{1}$

Triangle, $\mathrm{X}=3.17+0.08 \mathrm{Y}_{1}$ 


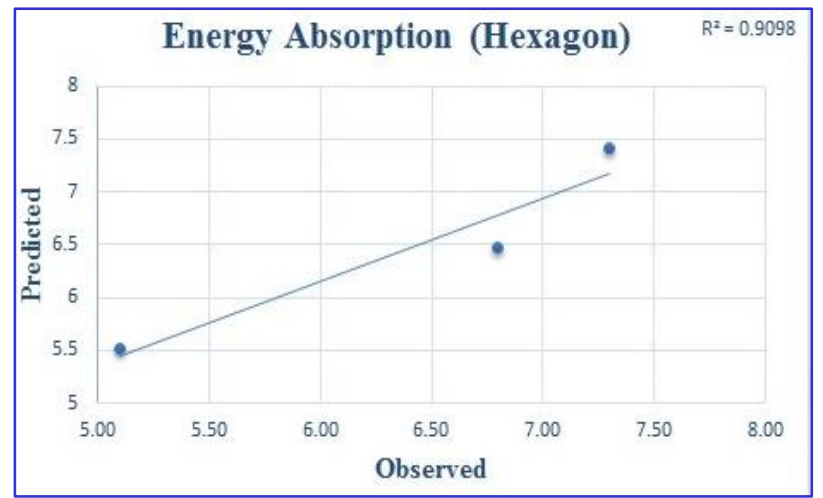

(a)

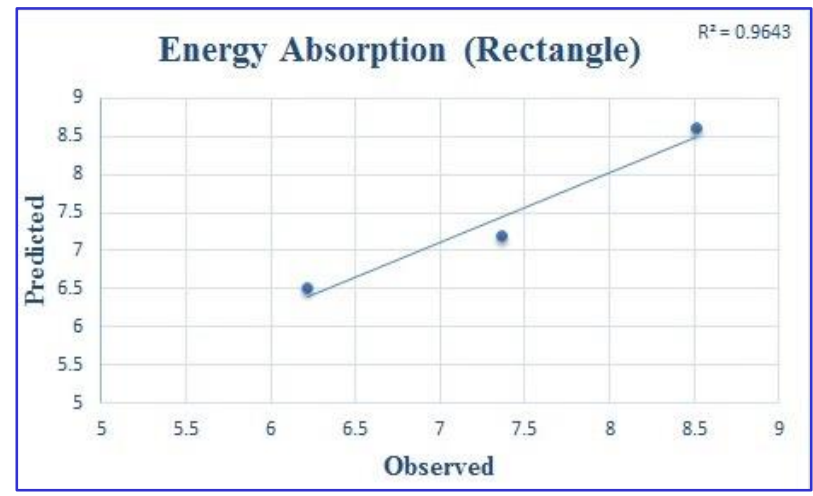

(b)

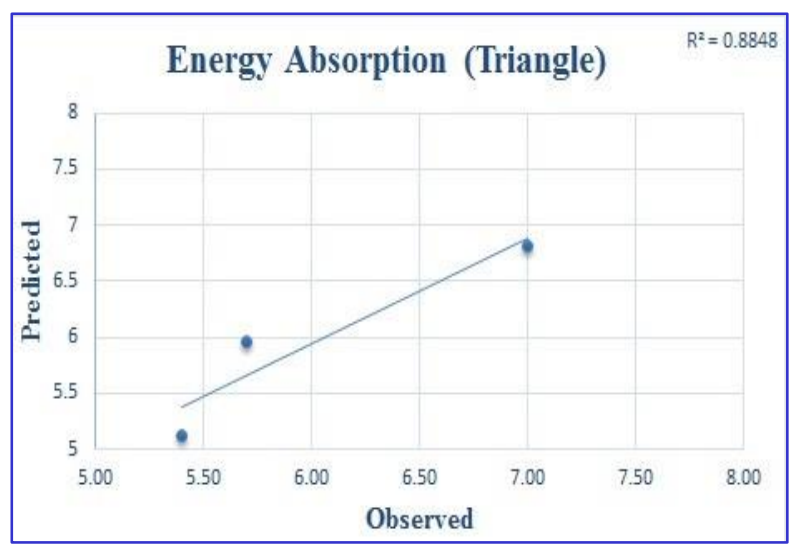

(c)

Fig. 8 Energy absorption observed with various (a) hexagon, (b) rectangular and (c) triangular patterns

The mechanical characteristics of onyx-carbon fiber-reinforced composites samples were measured and compared with the benchmark data, as shown in Table 2. The tensile strength aspect of mechanical properties was considered, which indicates the strength of the material under tensile loading. In comparison, it was observed that the PLA without addition of reinforcement yielded lesser strength. Therefore, it was evident that the reinforcement possesses hybridization property to obtain better and improved properties of composite materials [36, 39]. 
Among various fibers, including wood, carbon, onyx and such alike, it was significantly observed that the onyx-carbon fiber reinforced composite provided better properties with respect to higher impact, tensile strength and modulus [26, 38, 39]. Addition of onyx reinforcement to carbon fiber reinforced composite yielded higher tensile strength of $154.66 \pm 4.4 \mathrm{MPa}$, which was approximately 2 times that of simple carbon fiber reinforced composite and 5 times higher than the neat PLA material. Thus, it has been established that the onyx-carbon fiber reinforced PLA composite exhibited a higher strength, when compared with carbon fiber reinforced PLA and wood fiber reinforced PLA composites.

Table 2 Comparison of the tensile properties of onyx-carbon fiber composite with other similar materials

\begin{tabular}{|c|c|c|c|c|}
\hline S/No & $\begin{array}{c}\text { Type of 3D-printed } \\
\text { materials }\end{array}$ & $\begin{array}{l}\text { Tensile strength } \\
(\mathrm{MPa})\end{array}$ & $\begin{array}{c}\text { Tensile modulus } \\
\text { (GPa) }\end{array}$ & References \\
\hline 1 & PCL/PLA composites & 10 & 0.118 & Haq et al. [36] \\
\hline 2 & $\mathrm{Cu} / \mathrm{PLA}$ composite & 68.1 & 5.3 & Zhang et al. [37] \\
\hline 3 & Wood/PLA composites & 128.3 & 4.887 & Ayrilmis et al. [32] \\
\hline 4 & $\begin{array}{l}\text { Carbon fiber } \\
\text { composites }\end{array}$ & 100 & 4.31 & Mei et al. [38] \\
\hline 5 & PLA & 28 & 1.22 & \\
\hline 6 & PLA with carbon fiber & 80 & 0.72 & Li et al. [39] \\
\hline 7 & $\begin{array}{l}\text { PLA with modified } \\
\text { carbon fiber }\end{array}$ & 91 & 3.25 & \\
\hline 8 & $\begin{array}{l}\text { Onyx-carbon fiber } \\
\text { reinforced composites }\end{array}$ & $154.66 \pm 4.4$ & $6.97 \pm 0.46$ & Present work \\
\hline
\end{tabular}


Moving forward, it is expected in some engineering applications that materials should have resistance property against elastic deformation, such as tensile modulus. Hence, by comparing the tensile modulus of the onyx-carbon fiber reinforced PLA composite sample with other similar composite materials, it was similarly observed that the onyx-carbon fiber reinforced PLA composite exhibited a better property than the wood fiber reinforced PLA composite. It was twice the resistance to elastic deformation of carbon fiber reinforced PLA composite. This can be attributed to weaker carbon fiber-PLA adhesion or bonding that was associated with infilteration of PLA into carbon fiber and weak interlayer bonding during printing, unlike onyx-carbon fiber reinforced composite. Therefore, the 3D-printed onyx-carbon fiber reinforced PLA composite material can be used for engineering applications, having better properties when compared with other similar materials: neat or simple PLA, wood fiber reinforced PLA, carbon fiber reinforced PLA and modified carbon fiber reinforced PLA composites.

Some of the first industries to adopt wide application of carbon fiber reinforced polymeric composites are aeronautics and space, due to their outstanding properties. The carbon fiber reinforced polymeric composites have high moduli, which make them structurally appropriate materials. This has been demonstrated in this present study. Therefore, they replace many metallic, ceramic and alloy materials, such as aluminum, titanium, steel, among others in several engineering applications. Similarly, in sports and games, products that are widely made up of carbon fiber reinforced polymeric composites include, but are not limited to, rackets for tennis, golf clubs, soft bats, hockey sticks, arrows and archeries. Carbon fiber reinforced composites are typically used in imaging systems to support x-rayed or radiation-treated limbs.

In addition, carbon fiber reinforced composites are used without adding a considerable weight to provide required rigidity. This is important, because the lighter the blade of the wind 
turbine, the more power it generates [40]. Due to their high mechanical characteristics, carbon fiber reinforced composites attract an increasing number of applications in lightweight structures. Also, in many major civil aviation projects, such as Boeing 787 Dreamliner and Airbus A350, strong growth levels are already being observed [41]. Composites are commonly used in healthcare, as parts of equipment such as mammograms and state-of-the-art composite exoskeletons [42], to mention but a few. Most importantly, with several benefits of AM technology and better properties of the 3D-printed onyx-carbon fiber reinforced PLA composite, it has diverse promising and potential engineering applications, as an alternative material to the aforementioned composites.

\section{Conclusions}

The samples of additively manufactured onyx-carbon fiber reinforced composites have been produced based on various specifications (infill design/pattern and infill density/percentage), experimentally investigated and statistically analyzed. The 3D-printed specimens were mechanically tested in accordance with the ASTM standards to obtain their tensile properties and energy absorption rates. It was evident that the processing parameters significantly influenced the tensile characteristics of the onyx-carbon fiber reinforced PLA composite structures, in addition to the following concluding remarks.

- The rectangular pattern with infill density of $50 \%$ has both maximum tensile strength and modulus of $154.66 \pm 4.4 \mathrm{MPa}$ and $6.97 \pm 0.46 \mathrm{GPa}$, respectively as well as a superior strain force range, when compared with other counterparts.

- There was a significant improvement or an increase in the energy absorption rates (obtained from the impact test) of the onyx-carbon fiber reinforced PLA composites, with an increase in the infill density, especially with the rectangular pattern and infill density of $50 \%$. 
From the statistical results obtained from all the criteria for assessing the accuracy of the printed samples, the rectangular pattern provided the best values, when compared with other designs chosen for the experiment.

\section{Acknowledgements}

We hereby acknowledge and sincerely appreciate unalloyed supports from the managements of the following institutions: Kalasalingam Academy of Research and Education, Krishnankoil 626 126, Tamilnadu, India as well as the Rajalakshmi Institute of Technology, Chennai, Tamilnadu, India.

\section{Author disclosure statement}

In comparison with other patterns, this work gives more closely prediction in the rectangular design, using regression models. These models can further predict response of the quantities before and also guide practical applications.

\section{Funding information}

This research was not associated with any grant numbers or any institutions.

\section{References}

1. Dizon JRC, Espera AH, Chen Q, Advincula RC (2018) Mechanical characterization of 3Dprinted polymers. Addit Manuf 20:44-67. doi: 10.1016/j.addma.2017.12.002

2. Klift FVD, Koga Y, Todoroki A, et al (2016) 3D Printing of Continuous Carbon Fiber Reinforced Thermo-Plastic (CFRTP) Tensile Test Specimens. Open J Compos Mater 06:1827. doi: $10.4236 /$ ojcm. 2016.61003 
3. Ning F, Cong W, Hu Y, Wang H (2016) Additive manufacturing of carbon fiber-reinforced plastic composites using fused deposition modeling: Effects of process parameters on tensile properties. J Compos Mater 51:451-462. doi: 10.1177/0021998316646169

4. Melenka GW, Cheung BK, Schofield JS, et al (2016) Evaluation and prediction of the tensile properties of continuous fiber-reinforced 3D printed structures. Compos Struct 153:866-875. doi: 10.1016/j.compstruct.2016.07.018

5. Nakagawa Y, Mori K-I, Maeno T (2017) 3D printing of carbon fiber-reinforced plastic parts. The Inter Adv Manuf Technol 91:2811-2817. doi: 10.1007/s00170-016-9891-7

6. Rafiee M, Farahani RD, Therriault D (2020) Multi-Material 3D and 4D Printing: A Survey. Adv Sci 1902307. doi: 10.1002/advs.201902307

7. Zaman UKU, Boesch E, Siadat A, et al (2018) Impact of fused deposition modeling (FDM) process parameters on strength of built parts using Taguchi's design of experiments. The Inter J Adv Manuf Technol 101:1215-1226. doi: 10.1007/s00170-018-3014-6

8. Fernandez-Vicente M, Calle W, Ferrandiz S, Conejero A (2016) Effect of Infill Parameters on Tensile Mechanical Behavior in Desktop 3D Printing. 3D Print Addit Manuf 3:183-192. doi: $10.1089 / 3$ dp. 2015.0036

9. Camargo JC, Machado ÁR, Almeida EC, Silva EFMS (2019) Mechanical properties of PLA-graphene filament for FDM 3D printing. Inter J Adv Manuf Technol 103:2423-2443. doi: $10.1007 / \mathrm{s} 00170-019-03532-5$

10. Villalpando L, Eiliat H, Urbanic R (2014) An Optimization Approach for Components Built by Fused Deposition Modeling with Parametric Internal Structures. Procedia CIRP 17:800805. doi: 10.1016/j.procir.2014.02.050 
11. Alafaghani AA, Qattawi A, Alrawi B, Guzman A (2017) Experimental Optimization of Fused Deposition Modelling Processing Parameters: A Design-for-Manufacturing Approach. Procedia Manufact 10:791-803. doi: 10.1016/j.promfg.2017.07.079

12. Lanzotti A, Grasso M, Staiano G, Martorelli M (2015) The impact of process parameters on mechanical properties of parts fabricated in PLA with an open-source 3-D printer. Rapid Prototyp J 21:604-617. doi: 10.1108/rpj-09-2014-0135

13. Hart KR, Wetzel ED (2017) Fracture behavior of additively manufactured acrylonitrile butadiene styrene (ABS) materials. Eng Frac Mech 177:1-13. doi: 10.1016/j.engfracmech.2017.03.028

14. Li G, Zhao J, Jiang J, et al (2018) Ultrasonic strengthening improves tensile mechanical performance of fused deposition modeling 3D printing. Inter J Adv Manuf Technol 96:2747-2755. doi: 10.1007/s00170-018-1789-0

15. Tanikella NG, Wittbrodt B, Pearce JM (2017) Tensile strength of commercial polymer materials for fused filament fabrication 3D printing. Addit Manuf 15:40-47. doi: 10.1016/j.addma.2017.03.005

16. Ziemian S, Okwara M, Ziemian CW (2015) Tensile and fatigue behavior of layered acrylonitrile butadiene styrene. Rapid Prototyp J 21:270-278. doi: 10.1108/rpj-09-20130086

17. Hanon MM, Alshammas Y, Zsidai L (2020) Effect of print orientation and bronze existence on tribological and mechanical properties of 3D-printed bronze/PLA composite. Inter J Adv Manuf Technol 108:553-570. doi: 10.1007/s00170-020-05391-x 
18. Martínez J, Diéguez J, Ares E, et al (2013) Comparative between FEM Models for FDM Parts and their approach to a real mechanical behavior. Procedia Eng 63:878-884. doi: 10.1016/j.proeng.2013.08.230

19. Rajpurohit SR, Dave HK (2019) Prediction and Optimization of Tensile Strength in FDM Based 3D Printing using ANFIS. Springer Series in Advanced Manufacturing Optimization of Manufacturing Processes 111-128. doi: 10.1007/978-3-030-19638-7_5

20. Shahrain M, Didier T, Lim GK, Qureshi A (2016) Fast deviation simulation for 'fused deposition modeling' process. Procedia CIRP 43:327-332. doi: 10.1016/j.procir.2016.02.004

21. Kowalczyk M, Piorkowska E, Kulpinski P, Pracella M (2011) Mechanical and thermal properties of PLA composites with cellulose nanofibers and standard size fibers. Compos Part A Appl Sci Manuf 42:1509-1514. doi: 10.1016/j.compositesa.2011.07.003

22. Alkayyali, T, Ahmadi, A (2020) Fabrication of microfluidic chips using controlled dissolution of 3D printed scaffolds. J Appl Polym Sci 137:49524. doi:10.1002/app.49524

23. Tang, TO, Holmes, S, Dean, K, Simon, GP (2019) Design and fabrication of transdermal drug delivery patch with milli projections using material extrusion 3D printing. J Appl Polym Sci 137:48777. doi:10.1002/app.48777

24. Rajpurohit SR, Dave HK (2018) Flexural strength of fused filament fabricated (FFF) PLA parts on an open-source 3D printer. Adv Manuf 6:430-441. doi: 10.1007/s40436-018-02376

25. Wicaksono ST, Ardhyananta H, Rasyida A, Hidayat MIP (2018) Internal geometry effect of structured PLA materials manufactured by dropplet-based 3D printer on its mechanical properties. AIP Conference Proceedings 1945, 020065. doi: 10.1063/1.5030287 
26. Ferreira RTL, Amatte IC, Dutra TA, Bürger D (2017) Experimental characterization and micrography of 3D printed PLA and PLA reinforced with short carbon fibers. Compos Part B Eng 124:88-100. doi: 10.1016/j.compositesb.2017.05.013

27. Suresh G, Vivek S, Babu LG, et al (2019) Evaluation of mechanical behaviour of carbon fiber reinforced nanoclay filled IPN matrix composite. Mater Res Expr 6:125311. doi: $10.1088 / 2053-1591 / \mathrm{ab} 54 \mathrm{ec}$

28. Tian X, Liu T, Yang C, et al (2016) Interface and performance of 3D printed continuous carbon fiber reinforced PLA composites. Compos Part A Appl Sci Manuf 88:198-205. doi: 10.1016/j.compositesa.2016.05.032

29. Vijayaraghavan V, Garg A, Lam JSL, et al (2014) Process characterization of 3D-printed FDM components using improved evolutionary computational approach. Inter J Adv Manuf Technol 78:781-793. doi: 10.1007/s00170-014-6679-5

30. Pastrnak, A, Henriquez, A, Saponara, VL (2020) Parametric study for tensile properties of molded high-density polyethylene for applications in additive manufacturing and sustainable designs. J Appl Polym Sci 137:49283. doi:10.1002/app.49283

31. Kim, S, Korolovych, VF, Muhlbauer, RL, Tsukruk, VV (2020) 3D-printed polymer packing structures: Uniformity of morphology and mechanical properties via microprocessing conditions. J Appl Polym Sci 137:49381. doi:10.1002/app.49381

32. Ayrilmis N, Kariz M, Kwon JH, Kuzman MK (2019) Effect of printing layer thickness on water absorption and mechanical properties of 3D-printed wood/PLA composite materials. Inter J Adv Manuf Technol 102:2195-2200. doi: 10.1007/s00170-019-03299-9 
33. Rodríguez-Panes A, Claver J, Camacho A (2018) The influence of manufacturing parameters on the mechanical behavior of PLA and ABS pieces manufactured by FDM: A comparative analysis. Mater 11:1333. doi: 10.3390/ma11081333

34. Merchant R, Marchal WG, Wathen SA, Lind DA (2012) Basic statistics using Excel 2010 for: Statistical techniques in business \& economics. McGraw-Hill/Irwin, New York, NY

35. Vigneshwaran K, Venkateshwaran N (2019) Statistical analysis of mechanical properties of wood-PLA composites prepared via additive manufacturing. Inter J Polym Analy Character 24:584-596. doi: 10.1080/1023666x.2019.1630940

36. Haq RHA, Rahman MNA, Ariffin AMT, et al (2017) Characterization and Mechanical Analysis of PCL/PLA composites for FDM feedstock filament. IOP Conf Series Mater Sci Eng 226:012038. doi: 10.1088/1757-899x/226/1/012038

37. Zhang X, Chen L, Mulholland T, Osswald TA (2019) Characterization of mechanical properties and fracture mode of PLA and copper/PLA composite part manufactured by fused deposition modeling. SN Appl Sci doi: 10.1007/s42452-019-0639-5

38. Mei H, Ali Z, Yan Y, et al (2019) Influence of mixed isotropic fiber angles and hot press on the mechanical properties of 3D printed composites. Addit Manuf 27:150-158. doi: 10.1016/j.addma.2019.03.008

39. Li N, Li Y, Liu S (2016) Rapid prototyping of continuous carbon fiber reinforced poly lactic acid composites by 3D printing. J Mater Proc Technol 238:218-225. doi: 10.1016/j.jmatprotec.2016.07.025

40. Johnson, Todd. (2020, February 11). Uses for Carbon Fiber. Retrieved from https://www.thoughtco.com/uses-of-carbon-fiber-820394 
41. Pickering S, Liu Z, Turner T, Wong K (2016) Applications for carbon fiber recovered from composites. IOP Conf Series Mater Sci Eng 139:012005. doi: 10.1088/1757$899 x / 139 / 1 / 012005$

42. Kumar N, Gangwar AK, Devi KS (2018) Carbon Fibers in Biomedical Applications. Recent Developments in the Field of Carbon Fibers 83-102. doi: 10.5772/intechopen.75826 